\title{
DOES PUBLIC INSURANCE \\ CROWD OUT PRIVATE INSURANCE?
}

David M. Cutler

Jonathan Gruber

Working Paper No. 5082

\author{
NATIONAL BUREAU OF ECONOMIC RESEARCH \\ 1050 Massachusetts Avenue \\ Cambridge, MA 02138 \\ April 1995
}

We are grateful to Janet Currie and Aaron Yelowitz for their assistance in developing the Medicaid Eligibility programs used here, to Linda Blumberg, Janet Currie, Paul Gertler, Larry Katz, Chuck Nelson, and Joe Newhouse for helpful comments, and to the National Institute of Aging for financial support. This paper is part of NBER's research programs in Health Care, Health Economics and Public Economics. Any opinions expressed are those of the authors and not those of the National Bureau of Economic Research.

(C) 1995 by David M. Cutler and Jonathan Gruber. All rights reserved. Short sections of text, not to exceed two paragraphs, may be quoted without explicit permission provided that full credit, including $\odot$ notice, is given to the source. 


\title{
DOES PUBLIC INSURANCE \\ CROWD OUT PRIVATE INSURANCE?
}

\begin{abstract}
One popular option for health care reform in the U.S. is to make particular groups, such as children, eligible for public health insurance coverage. A key question in assessing the cost of this option is the extent to which public eligibility will crowd out the private insurance coverage of these groups. We estimate the extent of crowdout arising from the dramatic expansions of the Medicaid program during the 1987-1992 period. Over this time period, Medicaid eligibility for children increased by 50 percent and eligibility for pregnant women doubled. We estimate that between 50 percent and 75 percent of the increase in Medicaid coverage was associated with a reduction in private insurance coverage. This occurred largely because employees took up employer-based insurance less frequently, although employers may have encouraged them to do so by contributing less for insurance. There is some evidence that workers dropped coverage for their family and switched into individual policies.
\end{abstract}

David M. Cutler

Department of Economics

Harvard University

Cambridge, MA 02138

and NBER
Jonathan Gruber

Department of Economics

Massachusetts Institute of Technology

Room E52-274c

Cambridge, MA 02139

and NBER 
The recent debate over health care reform in the U.S. effectively ended public discussion of universal health insurance coverage. As a result, much attention is likely to be paid to partial alternatives, which offer free or subsidized coverage to particular groups. For example, a key feature of "compromise" reform plans is subsidized insurance coverage for the poor, and one option which remains politically popular is free or subsidized coverage for children (Boston Globe, September 12, 1994).

Partial coverage is not without its pitfalls, however. Perhaps the most important problem is the potential for public expansions to crowd out private insurance coverage. As the eligibility for public coverage expands, individuals may drop their private coverage and switch into public programs. This may substantially reduce the "bang for the buck" from public insurance coverage, as the costs of the program rise without commensurate increase in insurance coverage. This concern has been raised in discussions of coverage expansions (New York Times, August 21, 1994), but there is essentially no empirical evidence on its magnitude. ${ }^{2}$

Our goal in this paper is to provide evidence on the effect of public health insurance eligibility on private health insurance coverage. We do so by taking advantage of the large increases in eligibility for Medicaid -- the public insurance program for low income persons -- that occurred in the late 1980s and early 1990s. Historically, eligibility for Medicaid was tied to the receipt of cash welfare payments under the Aid to Families with Dependent Children program. Hence, eligibility was effectively limited to very low income women and children in single parent families. During the late 1980 s and early 1990 s, states were first permitted and then required to extend

\footnotetext{
'This is related to the general question of crowdout by social insurance programs: theoretical analyses of asset-tested social insurance programs typically suggest that they will crowd out private savings (Hubbard, Skinner, and Zeldes, 1995), and crowdout has been argued for empirically in the case of Social Security and private savings (Feldstein, 1974), and welfare and family transfers (Schoeni, 1994).
} 
Medicaid coverage to pregnant women and children with higher incomes, and in families with two parents. As a result, by 1992 , almost one-third of children were eligible for full public coverage, and over 40 percent of women of child-bearing age could receive public coverage for pregnancyrelated expenses.

We consider the effect of these Medicaid expansions on coverage by Medicaid, private insurance coverage, and the rate of uninsurance. We do so in two steps. First, we calculate the extent of crowdout, accounting for both the direct effects of own eligibility and the indirect effects of the eligibility of other family members. We estimate that between 47 and 74 percent of the increases in Medicaid coverage due to these expansions were offset by lower private insurance coverage. The key difference between these two estimates is the treatment of the conditional coverage provided by Medicaid for uninsured persons who may sign up for Medicaid when they become pregnant (women) or ill (children).

Second, we investigate the mechanisms through which crowdout might occur. We find no evidence that crowdout is caused by employers choosing not to offer health insurance as eligibility rises, although there may have been some increase in the share of premiums employers require employees to pay. Rather, crowdout appears to arise from employees not taking up coverage when it is offered. In addition, for those workers retaining their coverage, there is a move towards dropping coverage of dependents and covering one's self only.

The paper proceeds as follows. In Section I, we discuss theoretically the effect of public insurance expansions on private coverage. Section II provides background on the Medicaid expansions. Section III presents a first look at the crowdout question. Section IV considers how Medicaid eligibility has affected workers. Section V then calculates the net change in insurance coverage induced by Medicaid expansions. Section VI concludes. 


\section{I: Should Public Insurance Crowd Out Private Insurance?}

Consider a situation where all insurance is purchased by families, and insurance policies cover each member of the family individually. Initially, everyone has private coverage. If an individual is made eligible for free public coverage, she will drop her private insurance coverage if:

$$
\mathrm{V}_{\text {pub }}>\left(\mathrm{V}_{\text {priv }}-\mathrm{C}_{\mathrm{priv}}\right)
$$

where $V_{\text {pub }}$ and $V_{\text {priv }}$ are the value of public and private insurance and $C_{\text {priv }}$ is the cost of private insurance. The cost of private health insurance is extremely high. In 1987, the typical employee paid directly $\$ 483$ for health insurance, and had out-of-pocket costs for covered services of $\$ 779$, for a total of $\$ 1,262$. In addition, the individual's employer paid $\$ 2,078$ for health insurance, at least some of which might be perceived as a direct reduction in wages. ${ }^{2}$ Medicaid, in contrast, is generally free and has little cost sharing. Given this high cost, (1) suggests that there would be a substantial shift to public coverage.

In general, however, public coverage will not be valued as highly as private coverage. Because of low Medicaid reimbursement rates, providers are often reluctant to treat Medicaid patients (Currie, Gruber, and Fischer, 1995). In addition, individuals may not want to be enrolled in public programs, because of the stigma associated with public programs or the difficulty in enrolling. ${ }^{3}$ Finally, even if individuals are willing to accept public coverage they may be unsure

\footnotetext{
${ }^{2}$ These figures were tabulated by the authors from the 1987 National Medical Expenditure Survey.

${ }^{3}$ Takeup rates for AFDC, for example, are generally about two-thirds of eligibles (Blank and Ruggles, 1991). Potential Medicaid eligibles must complete lengthy and complex application forms, provide extensive documentation (such as birth certificates, pay stubs, and confirmation of child care costs) that many eligibles do not have, and attend several interviews with caseworkers. About onethird to one-half of all Medicaid applications are denied, and half of these denials are for procedural reasons; that is, because the applicant did not complete all of the necessary steps. In response, many hospitals have established special offices, or contracted with private companies, to assist Medicaid eligibles in completing these procedures (U.S. General Accounting Office, 1994).
} 
of its long run insurance value if the program changes or they lose eligibility. Since private insurance policies often exclude pre-existing conditions, people cannot shift costlessly between public and private coverage, so they may be reluctant to initially drop private insurance coverage.

Beyond these valuation differences, there are two issues that complicate the analysis of crowdout. The first is the fact that health insurance is generally sold only for individuals or for families, without gradations among types of dependents. Thus, a family that wants to cover both parents but not the children may find it impossible to do so with only one policy. Similarly, there is often no savings from enrolling some dependents on a policy but not others.

This lack of distinction among dependents may increase or decrease the amount of crowdout. To the extent that families value coverage of all members and some members cannot qualify for public coverage, crowdout is likely to be smaller than an individual-by-individual calculation would suggest. On the other hand, if the Medicaid subsidy is large, families may drop coverage of all members, even those who do not qualify for public insurance directly. ${ }^{4}$ These considerations suggest paying particular attention to the composition of coverage within the family, in addition to whether a family has coverage at all.

The second complication is that most private health insurance is provided through employment, rather than purchased individually. If workers do not receive the savings from foregoing employer-provided coverage in the form of higher wages or other benefits, they may choose to keep private coverage despite its high cost. While empirical evidence suggests that health insurance costs are passed back to workers (Gruber, 1994; Sheiner, 1994), this research has not established whether this passback occurs on a worker-by-worker basis, or at a broader level.

\footnotetext{
${ }^{4}$ This may be a rational reaction given the implicit insurance provided to those individuals not on Medicaid through provider "uncompensated care".
} 
In the absence of complete wage shifting, employers may encourage workers to drop coverage in other ways. One way to do this is to simply stop offering insurance to its employees. Alternatively, employers can reduce their contribution for health insurance premiums to encourage employees to drop coverage. Because of IRS non-discrimination rules, however, neither of these actions can be used selectively for those workers eligible for public insurance; if insurance is offered, it must be offered to all full-time workers, with common copayment rates for each insurance plan (Cutler and Madrian, 1995). As a result, both of these strategies increase the total cost of insurance for employees that do not qualify for public coverage, due both to the foregone tax subsidy for employer premium contributions and the much higher loading factors and less generous service coverage of insurance plans purchased in the individual market.

Thus, the link between health insurance and employment may increase or decrease the amount of crowdout. If worker-specific shifting is not possible, then crowdout may be reduced, as employers do not want to impose extra costs on those workers who are not eligible for Medicaid. If employers increase cost sharing or reduce coverage for all workers, however, the decline in private coverage may be greater than the increase in Medicaid eligibility. We explore the extent to which employers have taken these actions in the empirical work below.

\section{II: Medicaid Eligibility and Coverage Expansions}

Historically, Medicaid eligibility for pregnant women and children was tied to participation in the Aid for Families with Dependent Children (AFDC) program. This linkage with AFDC restricted access to the program in two ways. First, AFDC benefits are generally available only to 
single-parent households. ${ }^{5}$ Second, income cutoffs for AFDC are very low -- generally well below the poverty line. ${ }^{6}$

There were a number of other programs, offered at the discretion of the states, under which poor pregnant women and children could qualify for Medicaid, including the Medically Needy program (which allowed people to qualify for Medicaid if their incomes were somewhat above the cutoff but their medical expenses were particularly high); the Ribicoff option (which allowed states to cover children in two-parent families who met the AFDC income criteria); and other state options to cover pregnant women without children who met the AFDC income criteria. While these options relaxed the family structure restrictions for the program, eligibility was still restricted only to very poor persons.

To expand insurance coverage to the low income working population, in the late 1980 s and early 1990s, the linkage between AFDC coverage and eligibility for Medicaid was gradually weakened for pregnant women and children. Appendix Table 1 describes the legislation accomplishing this in more detail. The expansions substantially increased (in most states) the income that a family could have and still qualify for Medicaid, and at the same time provided these higher eligibility levels to all family structures, not just to single parent families. By 1992, states were required to cover all pregnant women and children under the age of 6 up to 133 percent of poverty (independent of family composition), and states were allowed to expand coverage up to 185 percent

${ }^{5}$ Married participants in the AFDC-UP program do qualify for Medicaid but this program is small. In 1990 only 5\% of the AFDC caseload qualified under AFDC-UP (U.S. House of Representatives, 1992).

'In 1987, the average income eligibility level across the states was roughly 60 percent of the poverty line. 
of poverty. ${ }^{7}$ In addition, children born after September 30, 1983, were mandatorily covered up to 100 percent of poverty (once again independent of family composition).

The important points to note are that states initially had different qualification limits, and they took up these options at different rates, so that there was a great deal of variation across states in both the size and timing of the expansions. There was also variation within states in the eligibilty of children, due to different age thresholds. ${ }^{8}$ We use this cross-state and cross-age variation in the size and timing of coverage expansions to identify our crowdout estimates.

We estimate eligibility for Medicaid using data from the March Current Population Surveys (CPS) for 1987 through $1992 .^{9}$ We include data for the post-1987 period since the CPS questionnaire has been consistent in that period. We impute eligibility to these women and to children in the CPS based on algorithms which are described in Currie and Gruber $(1994,1995) .^{10}$

The CPS is the largest nationally representative annual survey with the demographic data necessary to impute Medicaid eligibility and with information on insurance coverage. There are some drawbacks, however. First, the CPS does not indicate whether a woman is pregnant; we therefore impute eligibility for all women of child-bearing age (15-44). Second, the CPS interviews individuals in March about their insurance coverage in the previous year, so that the questions about

${ }^{7}$ Several states expanded coverage above 185 percent of poverty, but they did not receive federal matching funds for this group.

${ }^{8}$ See Yelowitz (1993) for a more detailed discussion of these "age notches".

9Since the CPS asks about insurance and income with a one year lag, the data are from the 1988 through 1993 surveys.

10 Since Medicaid coverage is determined on a monthly basis and our data are on an annual basis, some people will naturally be on Medicaid but not determined to be eligible. Given this problem, our Medicaid eligibility imputation is fairly accurate. Of the children on Medicaid in 1992, over three-quarters are imputed to be eligible for Medicaid. Similarly, 95 percent of women of child-bearing age who are on Medicaid were determined to be eligible for Medicaid. 
insurance coverage may be a mixture of information about the past year and the current situation, rather than a consistent answer to either. Finally, individual family members in the CPS may not accurately distinguish the Medicaid coverage of their family members from the coverage of themselves. Parents whose children are covered by Medicaid, for example, may respond that they too are covered, even if they are not. This might lead to an overstatement of the effects of eligibility expansions on Medicaid coverage, a point we return to below. ${ }^{11}$

Table 1 shows trends in Medicaid eligibility and coverage for children and women of childbearing age. For both groups, there was a dramatic expansion in eligibility. Eligibility for children rose by over 50 percent, to 27 percent of all children by 1992 . For women of child-bearing age, eligibility for Medicaid in the event of pregnancy doubled over this six year period, and reached $\mathbf{4 5}$ percent of women by 1992. As the second and fourth columns indicate, coverage also increased substantially, although by less than eligibility. Coverage of children rose by 6 percentage points, and coverage of women of child-bearing age rose by 3 percentage points.

This overall trend masks substantial heterogeneity across the states in eligibility changes, as documented in Currie and Gruber $(1994,1995)$. In the South, AFDC eligibility has traditionally been very low, and thus eligibility increases were most pronounced; in the Northeast and Far West,

${ }^{11}$ This problem is exemplified by the case of adult men who report receiving neither AFDC nor Supplemental Security Income (SSI); for this group, there is no possibility of receiving Medicaid, but 1.4 percent of them report receipt in 1987 and 2.4 percent report it in 1992. In 99 percent of these cases, someone else in the family also reported receiving Medicaid coverage. This problem might arise from the fact that respondents are first asked if anyone in the family is covered by Medicaid, and later on they are asked about the coverage of individual family members. At this later point, respondents may simply answer that all household members are covered. We are extremely grateful to Chuck Nelson of the Census Bureau for discussing these issues with us. 
the eligibility increases were much smaller. ${ }^{12}$

The potential for these expansions to crowdout private coverage is evidenced in Table 2. For each child and woman of child-bearing age in 1987, we estimated eligibility under the rules in place in that year, and (after appropriately inflating their incomes) the rules that were in place in 1992. As the second row shows, 30 percent of those eligible for Medicaid in 1987 were insured privately, 50 percent were insured publicly, and 25 percent were uninsured. Among the group projected to be made eligible by the expansions (the third row), however, almost two-thirds were privately insured. Only 15 percent had public coverage, and one-quarter were uninsured. Indeed, it is striking that the rate of uninsured is the same for those made eligible by the expansions and those who were previously eligible. Thus, as Medicaid eligibility limits increased, the population newly acquiring eligibility was increasingly populated by those with private coverage, and no more likely to be uninsured.

In fact, the rise in Medicaid coverage over this period was roughly commensurate with a decline in private insurance coverage. Figures $1(\mathrm{a})$ and (b) show the trends in Medicaid coverage, private insurance coverage, and uninsurance for children and women of child-bearing age. In both cases, the percent of the population with Medicaid coverage increased dramatically, particularly after 1989. In both cases, private coverage fell substantially at exactly the same time. As a result, the fall in the percent uninsured was not very large for children; for women of child-bearing age, the uninsurance rate actually rose.

While these Figures are suggestive of a crowdout, they are not definitive. There was a sizeable recession in the early 1990 s. Presumably, recessions reduce private coverage and increase

\footnotetext{
${ }^{12}$ Most of the increase in eligibility in this period was due to the expansions beyond AFDC, and not changes in AFDC-related eligibility; for pregnancy, $95 \%$ of the eligibility increase was due to the expansions; for children, $85 \%$ was due to the expansions.
} 
the percent of the population with Medicaid coverage. In the next section, we use cross-sectional variation in Medicaid eligibility to more convincingly estimate the extent of crowdout.

\section{III: First Estimates of Crowd-Out}

We begin by using data on children and women of child-bearing age to estimate equations of the effect of own Medicaid eligibility on own insurance coverage. Our specification is:

$$
\operatorname{COV}_{\mathrm{i}}=\beta_{1} \mathrm{ELIG}_{\mathrm{i}}+\mathrm{X}_{\mathrm{i}} \beta+\Sigma \alpha_{\mathrm{z}} \text { state }_{\mathrm{i}}+\Sigma \alpha_{\mathrm{t}} \mathrm{time} \mathrm{i}_{\mathrm{i}}+\epsilon_{\mathrm{i}}
$$

$\mathrm{COV}_{\mathrm{i}}$ is an indicator for insurance coverage, either Medicaid, private insurance, or uninsured. ELIG $_{i}$ is a variable measuring the eligibility of individual $i$ for Medicaid. We return later to the question of whether individual or family eligibility is the most appropriate independent variable. When Medicaid is the dependent variable, $\beta_{1}$ measures the marginal takeup rate for public insurance. For other forms of insurance coverage, $\beta_{1}$ measures the crowdout effect of increased eligibility.

$\mathrm{X}$ is a set of demographic controls, including the race of the child or woman; the sex of the child; the marital status of the woman; the number of persons and the number of workers in the household; and the type of family (male and female head, male head only, female head only). Table 3 reports means of these demographic variables.

Several points about equation (2) deserve discussion. The first is pooling by age. We estimate equation (2) for all children jointly, and for women of child-bearing age. Without additional controls, however, the estimates for children may be biased. Infants (aged 0), for example, are generally more likely to be eligible for Medicaid than are older children. It may also be the case that infants are less likely to have private insurance coverage than are older children -- perhaps because one parent is at home with the children. Without controlling for age, our regressions would explain lower private insurance coverage for younger children by increased Medicaid eligibility, 
when the relation is not causal. To control for this, we include age dummy variables for children, and age group dummy variables for women. ${ }^{13}$

The second concern is the eligibility measure. Ideally, we would use actual eligibility of each individual as the independent variable. Using actual eligibility is not appropriate, however. First, there may be omitted covariates which are correlated with both insurance coverage and Medicaid eligibility. While we control for a number of the determinants of Medicaid eligibility, ELIG depends on these controls in a non-linear manner, which is difficult to fully capture in the regression. Second, eligibility is likely to be measured with some error, for example because actual eligibility is determined on a monthly basis and we only have annual income measures.

The natural solution to these problems is to instrument individual eligibility using state-year legislative characteristics. Using variation from the legislative environment only eliminates bias from omitted individual factors and from error in accurately determining eligibility. ${ }^{14}$ To perform this estimation, we first select a national random sample of 300 children of each age and 3000 women of child-bearing age in each year. We then calculate the fraction of children and women in this sample who would be eligible for Medicaid given the rules of each state in that year. In essence, our measure just weights the rules in each state by their effects if applied nationally. ${ }^{15}$ We

\footnotetext{
${ }^{13}$ Our children regression has dummy variables for ages 0 through 18 . The regression for women has dummy variables for ages 15-18, 19-29, 30-39, and 40-44.

${ }^{14}$ To the extent that measurement error arises from errors in our representation of the legislative regime, however, the error will remain.

${ }^{15}$ An alternative instrument is the average eligibility of children and women of child-bearing age in each state/year/age cell. A national random sample has two advantages relative to this state average measure. First, the small sample sizes in many states make the latter estimates quite noisy. Second, and more importantly, a state-specific measure is not immune to state-specific economic shocks. A state in which income is transitorily low, for example, may have greater Medicaid eligibility and lower private coverage.
} 
instrument for individual eligibility with this "simulated percent eligible" measure. ${ }^{16}$

The one potential problem with this measure is that it relies on the exogeneity of state legislation. If states expand Medicaid eligibility because of reductions in private coverage, it could lead to a spurious crowdout estimate. This "endogenous legislation" scenario is unlikely to be very problematic in our context since much of the permanent variation in eligibility is coming from federal mandates on states of differing initial eligibility generosity, rather than state-specific expansions beyond the federal mandates. For example, 95 percent of the children made eligible between 1987 and 1992 qualified for Medicaid under Federally-imposed guidelines; only 5 percent were eligible because of state coverage beyond the Federal mandate. For women of child-bearing age, 80 percent of those newly eligible were eligible because of the Federal mandate. ${ }^{17}$

More generally, however, there may be omitted factors which are correlated with both the (state or federally mandated) eligibility changes and insurance coverage in that state. To address this, we include full sets of dummy variables for states and years. In the children regressions, we have also experimented with including full sets of age-year and state-year dummy variables, to capture time trends in insurance coverage which vary by age group or location. The results were very similar to those reported below in every case. ${ }^{18}$

${ }^{16}$ This approach follows Currie and Gruber $(1994,1995)$. Individual eligibility should increase, on average, about one-for-one with simulated eligibility, suggesting a first stage coefficient of about 1. In fact, the first stage coefficients are $0.842(0.013)$ for children, and $0.949(0.026)$ for women.

${ }^{17}$ States did have some discretion as to the timing of the eligibility expansions. But if we restrict our regressions to the first and last years of our sample, thus using only the permanent variation in eligibility, we get very similar results.

${ }^{18}$ That is, in our basic regression framework we are identified by interactions of year and age; state and year; state and age; and state, year, and age. When we include the first two second order interactions in the regression, the results are unchanged. We have also reestimated all of the crowdout regressions in Parts IV and V with a full set of state-year interactions as well, and the results are once again quite similar. 
Table 4 reports estimates of equation (2). The first three columns report the effect of eligibility expansions on coverage of children; the latter three columns report the results for women of child-bearing age. ${ }^{19}$ Within each set of columns, there are separate regressions for Medicaid coverage, private health insurance coverage, and uninsurance. All regressions are run as linear probability models for ease of computation with our sizeable samples and for consistency of our instrumental variables procedure. ${ }^{20}$ We also weight the regressions to be representative of national totals.

In all cases, the demographic controls enter in the expected direction. Whites, households with a male head, households with more workers, and households with fewer people are more likely to have private coverage, and less likely to have Medicaid or be uninsured.

The first row shows the effect of Medicaid eligibility. There is a significant effect of eligibility on coverage for children, with an estimated takeup rate of 24 percent. This is substantially below the average takeup rates for other public programs estimated in the literature. These marginal and average estimates are not directly comparable, however, when the program is expanding to cover a population which generally already has private insurance coverage. Indeed, of the children that were made newly eligible between 1987 and 1992, only 27 percent were uninsured in 1987 (based on calculations such as those in Table 2). Thus, if the increase in coverage were only among the uninsured population, the takeup rate would be almost 90 percent. Of course, given that some of

\footnotetext{
${ }^{19}$ Female 15-18 year-olds who are children are included in the child sample, and those that are household heads or spouses are included in the adult sample. Those who are children actually have two options for eligibility: as children, and (for the costs of pregnancy) as pregnant women. For the purposes of these regressions, we consider only their eligibility as children. When we expand the measure to family dollars, we account for the pregnancy option as well.

${ }^{20}$ We have reestimated some of our regressions using probit models in the second stage and the results are quite similar.
} 
the Medicaid increase reflects dropping of private coverage, this estimate is an upper bound on the true take-up rate.

For women, there is no statistically significant increase in Medicaid coverage as eligibility expands. Roughly 11 percent of women are pregnant in any given year, so the estimated takeup rate is only about 7 percent. ${ }^{21}$ Thus, the expansions do not appear to be affecting coverage throughout the pregnancy. ${ }^{22}$

The remaining columns estimate the effect of Medicaid eligibility on private insurance coverage and the rate of uninsurance. The increase in the Medicaid population plus the fall in private insurance need not sum to the effect on the uninsured because of coverage under other government programs (CHAMPUS and Medicare), ${ }^{23}$ and because individuals may have both Medicaid and private coverage in a given year.

As Medicaid eligibility expands, there is a statistically significant offset in private insurance coverage for both children and women of child-bearing age. For children, each 10 percentage point increase in Medicaid eligibility results in a .74 percentage point decline in private insurance

${ }^{21}$ All women who give birth in a year must have been pregnant at some time during that year. In addition, between $2 / 3$ and $3 / 4$ of women whose pregnancies begin in one year will give birth in the next year. With a birth rate of 6.5 percent, the percent pregnant in any year is at most $(1+.75) * 6.5$, or 11.4 percent. Since 95 percent of the increase in Medicaid eligibility for women arose from expansions for prenatal care, considering the share of women who are pregnant is an accurate estimate of the group affected by the eligiblity changes. Since 24 percent of those made eligible by the 1987-1992 rule changes were uninsured, the takeup rate among the uninsured population is roughly 30 percent.

${ }^{22}$ Note that this finding is consistent with the results of Currie and Gruber (1994), who find that Medicaid eligibility changes closely targeted to AFDC-like populations led to increased Medicaid coverage and improved birth outcomes, but that the type of broad expansions to higher income groups on which we focus here had little impact on either coverage or outcomes.

${ }^{23}$ CHAMPUS is the program for dependents of active duty military; Medicare may cover those under 65 who are dependents of elderly or who are disabled. As expected, Medicaid eligibility has only a small and insignificant effect on coverage through these sources. 
coverage. On net, the rate of uninsurance for children falls, but by only one-half as much as the increase in Medicaid coverage. For women, each 10 percentage point increase in Medicaid eligibility results in a .45 percentage point decline in private insurance coverage, and a .46 percentage point increase in uninsurance. Recall that these findings are independent of general time trends in private insurance coverage and uninsurance, since the model includes a full set of year dummy variables.

What do these findings imply for the extent of crowdout? One estimate of crowdout is the reduction in private insurance coverage accompanying the increase in Medicaid coverage. For children, this estimate is $.074 / .235$, or 31 percent. If the goal of the expansions is to reduce the rate of uninsurance, an alternative calculation is the percent of the increase in Medicaid that was not associated with a reduction in the uninsured population. For children, this estimate is $1-.119 / .235$, or 49 percent.

For women, both of these estimates suggest crowdout of over 100 percent. The issue of crowdout is more complicated for women, however, because the coverage that they receive through the public sector is only conditional coverage -- health insurance when they have one particular medical need (pregnancy) but not at all times. Thus, the right notion of coverage should add in to the direct coverage estimate the implicit coverage that all women have for pregnancy. We return to this point below.

\section{Changes in Employer-Based Coverage}

Having documented the reduction in private health insurance as Medicaid eligibility increases, we now consider the mechanisms through which this crowdout occurs. Most (nearly 90 percent) private health insurance in the United States is provided through employment. Thus, to understand 
the reduction in private health insurance, we focus on employer-provided insurance. Following the discussion of Part I, there are at least four mechanisms through which employer-provided coverage could fall as Medicaid eligibility increases. First, employers may choose not to offer health insurance as more employees become eligible for public coverage. Alternatively, employers may continue to offer insurance, but they may reduce their contributions for insurance premiums, or otherwise reduce the generosity of health insurance benefits in an effort to get those employees with family members eligible for Medicaid to drop coverage. Third, workers may choose to decline coverage for themselves and their family, even with no change in employer behavior. Finally, workers who are not themselves eligible for Medicaid but who have eligible dependents may decide to maintain coverage for themselves but to decline coverage for those dependents. We investigate each of these responses. ${ }^{24}$

\section{IV.A Empirical Framework}

To estimate these responses, we need to incorporate the effect of Medicaid expansions on the family as a whole. Fathers, for example, will be affected by Medicaid expansions for their children, even if they are not affected on their own. Similarly, the private insurance coverage of mothers might be affected not only by their own eligibility for pregnancy, but by the eligibility of their children as well.

To examine Medicaid generosity at the family level, we estimate the share of family dollars that would be covered by Medicaid. We first sort individuals into "health insurance units" (HIUs) -

\footnotetext{
${ }^{24}$ Other mechanisms could include moral suasion or other financial incentives to drop insurance. There could also be a general equlibrium effect arising from the fact that Medicaid generally reimburses below private market rates: as Medicaid coverage rises, providers may try to maintain their incomes by charging higher prices to privately insured patients, lowering the demand for private insurance. We are unable to distinguish these hypothesis from the more general takeup issue.
} 
- the group for which health insurance is traditionally sold. A health insurance unit consists of a family head, spouse, and any children under 19 (or under 23 who are full time students). Other relatives, while they may be in the same Census family, are typically not covered by the same health insurance policy. ${ }^{25}$

For each health insurance unit, our measure of Medicaid eligibility is the weighted average of Medicaid covered spending, where the weights are each person's share of expected health spending. ${ }^{26}$ That is:

$$
\text { \%HIU Dollars }=\left(\Sigma_{k} \text { SPEND }_{k} * \text { ELIG }_{k} * N_{U} M_{k}\right) /\left(\Sigma_{k} \operatorname{SPEND}_{k} * N_{U} M_{k}\right)
$$

where $\mathbf{k}$ indexes single year age groups of children, and broader age groups for adults. ${ }^{27}$ SPEND $_{k}$ is the expected health spending in a year for that age group. It is based on data from the 1987 National Medical Expenditure Survey (NMES), the most recent national survey of individual medical spending. Appendix Table 2 shows average spending by age and sex.

ELIG $_{k}$ is the eligibility for Medicaid of family members in age group $k$, and NUM is the number of family members in that age group. ${ }^{28}$ By definition, eligibility is zero for men 19 and older and women 45 and older. For children below age 15 ELIG is simply a 0/1 variable. For women of child-bearing age, the eligibility measure is more complex, since in some circumstances

\footnotetext{
${ }^{25}$ The regressions in Table 4 included demographic information about health insurance units, rather than families.

${ }^{26}$ An alternative strategy would be to simply measure the fraction of HIU members that are covered by Medicaid. This has the disadvantage that it does not account for the fact that covering an older child is less costly than covering a 30 year-old woman, and for the fact that some of the expansions only cover pregnancy and not other expenditures. We have explored specifications using unweighted measures of eligibility, with similar results.

${ }^{27}$ We divide adults into those age $19-29,30-39,40-49,50-59$, and 60-64. We further divide women into ages $40-44$ and $45-49$ because pregnancy is assumed to occur only in the first group.

${ }^{28}$ Note that all members of a given age group within a family will have the same eligibility status.
} 
(ie. AFDC eligibility) all of spending will be covered while in other circumstances only pregnancyrelated spending will be covered. To address this, we divide the eligibility measure into two parts: full-year eligibility (as either a child or an adult), and incremental eligibility for pregnancy-related coverage only. We weight the probability of full-year eligibility by total annual spending, and the probability of coverage for pregnancy only by the expected cost of pregnancy. ${ }^{29}$

Trends in family eligibility for Medicaid are summarized in the final column of Table 1. The percent of family dollars covered by Medicaid rises over time, from 8 percent in 1987 to over 12 percent in 1992.

Ideally our independent variable would be a proxy for $\left[\mathrm{V}_{\text {pub }}-\left(\mathrm{V}_{\text {priv }}-\mathrm{C}_{\mathrm{priv}}\right)\right]$. Calculation of the cost of private insurance on a worker-by-worker basis, however, would require information on both the employee share of premium payments and the expected out of pocket costs incurred by the employee under their plan. While the CPS has a crude measure of the first, it has no information on the second. Furthermore, the employee's share of the premium is, we argue below, endogenous to Medicaid policy. We thus use only the value of Medicaid spending to the family, as measured by the share of costs made eligible for public insurance, to estimate crowdout.

Since we are estimating models for worker coverage, we augment our regression equation (2) in several ways. First, we add controls for education, 1-digit industry and occupation, firm size, full-time/part-time and full-year/part-year work, and the state/year unemployment rate. A first pass estimating equation is therefore:

\footnotetext{
${ }^{29}$ The expected cost of pregnancy is the product of the age-specific fertility rate and total annual spending for women who had a child during the survey year. This measure may overstate or understate the true cost of pregnancy. Because it includes spending on all services, it is likely to overstate pregnancy costs. Because the survey is only for one year, however, it will understate costs for women who incurred some pregnancy-related costs in previous years. Our resulting estimate of pregnancy costs is $\$ 3,996$ in 1987 , which is close to other estimates in the literature.
} 
(2') $\operatorname{COV}_{\mathrm{i}}=\beta_{1} \%$ HIU Dollars $\mathrm{i}_{\mathrm{i}}+\mathrm{X}_{\mathrm{i}} \beta+\Sigma \alpha_{\mathbf{s}}$ state $_{\mathrm{i}}+\Sigma \alpha_{\mathrm{i}}$ time $_{\mathrm{i}}+\epsilon_{\mathrm{i}}$.

There are two factors to consider in estimating equation (2'). The first issue is controlling for the demographic structure of the HIU. As noted above, we do not want to be identified simply by the age of the children, since families with older or younger children may have different levels of private insurance coverage for reasons independent of Medicaid eligibility. Indeed, the problem of family structure is more complex than just the age distinction suggests. Consider two families with the same income, but where the adults are of different ages. Since spending increases with age, families with older adults will have a smaller fraction of spending covered by Medicaid than families with younger adults, holding constant the eligibility of the children. Families with older adults may be more likely to have private insurance coverage for other reasons, however. Without controlling for these age differences, the estimates of crowdout will be biased.

To control for these factors, we note that in a given family, a child or women in age group $k$ accounts for $\operatorname{SPEND}_{k} /\left(\Sigma_{k} \operatorname{SPEND}_{k} * \mathrm{NUM}_{k}\right)$ share of expected family spending. Therefore, the importance of each age group in total family spending -- with constant Medicaid policy -- can be represented as:

$$
\mathrm{DEMOG}_{\mathrm{k}}=\operatorname{SPEND}_{\mathrm{k}} * \mathrm{NUM}_{\mathrm{k}} /\left(\Sigma_{\mathrm{k}} \text { SPEND }_{k} * \mathrm{NUM}_{\mathrm{k}}\right)
$$

Once these family structure variables are included in the regression, ${ }^{30}$ the variation remaining in our Medicaid eligibility measure is due entirely to differing eligibility rates by state, year, and age, not to the demographic composition of the family. ${ }^{31}$ Our final estimating equation is therefore:

\footnotetext{
${ }^{30}$ Note that there are 22 DEMOG terms -- one for each age child, and three for women of different ages.

${ }^{31}$ That is, we can rewrite (3) as $\%$ HIU Dollars $=\left(\Sigma_{k}\right.$ DEMOG $\left._{k} * E_{1} G_{k}\right)$. Thus, when we control for the full set of $D E M O G_{j}$ controls, we are only identifying the model from differences in eligibility regimes, interacted with individual family structure, and not from family structure itself.
} 
(2') $\operatorname{COV}_{\mathrm{i}}=\beta_{1} \%$ HIU Dollars $+\mathrm{X}_{\mathrm{i}} \beta+\mathrm{DEMOG}_{\mathrm{i}, \mathrm{k}} \gamma_{\mathrm{k}}+\Sigma \alpha_{\mathbf{s}}$ state $_{\mathrm{i}}+\Sigma \alpha_{\mathrm{t}} \mathrm{time}_{\mathrm{i}}+\epsilon_{\mathrm{i}}$.

In estimating equation (2'"), we are once again concerned about both omitted variables bias and measurement error from using actual family Medicaid eligibility. Thus, we create an instrument of the form of (3), where each individual age group k's eligibility is replaced by the simulated eligibility for that state/year/age cell, based on the national sample described above.

To be concrete, consider two families, each with a 25 year-old male and a 1 year-old child, and with the same income. The first family is in a state where the child is eligible for Medicaid, and therefore has eligible spending of $(1266 / 1266+625)$, or 67 percent. The second family is in a state where the child is not eligible for Medicaid, and therefore has eligible spending of 0 . Suppose that average Medicaid eligibility for 1 year-olds is 30 percent in the first state and 20 percent in the second state. Then, the first family would have predicted eligibility of $\left(1266^{*} .3\right) /(1266+625)$, or 20 percent, and the second family would have predicted spending of $\left(1266^{*} .2\right) /(1266+625)$, or 13 percent. Our first stage regression explains eligibility for each family with these predicted eligibility differences. ${ }^{32}$

We restrict the sample to workers aged 24 and older. ${ }^{33}$ We exclude young workers because the distinction between working and school enrollment is critical in determining an individual's health

\footnotetext{
${ }^{32}$ On average, we would expect actual eligibility to increase one-for-one with predicted eligibility, suggesting a first stage coefficient of about 1 . Indeed, for our basic specification of worker eligibility (column (4) of Table 5), the first stage coefficient is $0.917(0.009)$.

${ }^{33}$ Focusing only on workers potentially creates a bias if Medicaid policy affects labor supply decisions. The direction of this bias is not obvious: for single women, the Medicaid expansions induced labor supply by allowing them to leave welfare and retain insurance for themselves and their children (Yelowitz, 1993); but if some married women are working solely to provide insurance for their family, then the availability of public insurance may induce them to stop working. In any case, we find strong insurance effects on males as well as females, suggesting that our findings are not driven by any labor supply response. This is a worthy topic for future work, but not one that we consider further.
} 
insurance unit, and we do not want to be biased by movements into and out of schooling.

\section{IV.B The Distinction Between Offering and Takeup}

We begin with the effects of Medicaid eligibility on the decision of employers to offer health insurance and the decision of employees to takeup this coverage. Unfortunately, we cannot learn about employer insurance offering with our March CPS data. The March Supplement asks only whether workers have insurance coverage, not whether they were offered coverage but chose to turn it down. In order to separate these effects, therefore, we turn to data from the May 1988 and April 1993 Employee Benefits Supplements to the CPS. These supplements collected information about a variety of workplace benefits for a subsample of workers, including whether their employer offers insurance and whether the employee chose to be covered. Because the supplements are small and cover only two years, there are fewer than one-tenth as many workers in these data as are in the full set of March surveys.

We are also hampered by the fact that no survey of workers accurately captures information about the firm as a whole. Presumably, firms should decide to stop offering insurance if a significant share of total employees value Medicaid highly. Unfortunately, we know only about the worker who is surveyed, not about his or her coworkers. As an approximation, we simply use the worker-level information when we estimate the probability that the firm offers insurance. To the extent that the workers we observe are not representative of workers at the firm as a whole, therefore, our estimates of the propensity to offer insurance may be misstated.

The probability that a worker is offered insurance has fallen over time, from 85 percent in 1988 to 77 percent in 1993 . The takeup rate has also fallen, but not by as much (from 85 percent in 1988 to 83 percent in 1993). General time series trends in offering and coverage, however, will 
be captured in the year dummies included in the regression.

Table 5 presents estimates of the effect of Medicaid eligibility on offering and takeup of health insurance. The first three columns report the results for the 1988 and 1993 Supplement Data. ${ }^{34}$ In the first column, we report the result for coverage through an employment-based policy. The next two columns then separate coverage into whether health insurance is offered, and whether coverage is chosen. In each case, the controls have the expected signs. Males, whites, and full-time workers are generally more likely to be offered coverage and to accept this coverage.

Increasing the share of dollars made eligible for Medicaid reduces the probability that a worker has health insurance coverage. Each 10 percentage point increase in Medicaid eligibility lowers the probability of employer coverage by 1.8 percentage points. This result is large and statistically significant, although the standard error is quite large as well. Since the sample size in the Supplement data is small and it covers only two years, we use the annual March data to confirm this result. These results are in the fourth column of the Table. The coefficient on Medicaid eligibility is a bit smaller in the March data, but of the same order of magnitude. The standard error of the estimate with the March data is, of course, much smaller than that with the Supplement data.

The next two columns divide the coverage result into the probability that employers offer insurance, and the probability that workers takeup this insurance. There is no effect of Medicaid eligibility on the decision to offer insurance; while the standard error is once again large, the point estimate is approximately zero. At the same time, there is a large and statistically significant effect of Medicaid eligibility on the takeup rate, conditional on being offered insurance. Thus, the estimates suggest that all of the reduction in worker coverage is coming through lower takeup rates,

\footnotetext{
${ }^{34}$ In the Supplement data, we know only whether the worker is part or full time, while in the March data we know if he/she is also part or full year. This leads to a slightly different control set for the Supplement and March data.
} 
not reduced employer offering of insurance.

\section{IV.C Changes in Cost Sharing}

If employees are choosing to decline coverage more as Medicaid eligibility increases, it may be because employers are encouraging them to do so. One natural way to do this is by increasing the share of health insurance premiums paid by workers. In 1991, the typical employer paid about 86 percent of a single premium, but only about 60 percent of the additional costs for dependents. ${ }^{35}$ While neither CPS survey reports the share of the premium paid for by employers, the March survey does ask whether employers pay for all, part, or none, of the cost of the insurance policy. Among workers with insurance, 36 percent report that their employer pays all of the premium, 59 percent report that the employer pays some of the premium, and 5 percent report that the employer pays none of the premium.

To examine how cost sharing responds to Medicaid eligibility, the final three columns of Table 5 present regressions for the probability that an employer pays for all, part, or none of the cost of health insurance. The regressions are estimated for all workers, not just those with health insurance, in order to avoid selection bias from the change in the number of workers covered; as a result, the sum of the three coefficient equals the drop in worker coverage in column (4). The results show a significant reduction in the probability that employers pay for all or none of the costs of health insurance. The probability that employers pay for some of the cost of insurance falls, but only slightly.

The fact that the number of workers with coverage is changing makes it impossible for us

\footnotetext{
${ }^{35}$ According to the Health Insurance Association of America, the average employer paid 72 percent of a family premium. A typical family policy costs 2.5 times a single policy, yielding the 60 percent marginal payment estimate.
} 
to definitively measure how individual employers have changed their payment practices. If the decline in takeup rates were coming entirely from workers whose employer paid for all of the premium, for example, then the remaining employers would be disproportionately shifting into paying the whole premium. ${ }^{36}$ If the decline in coverage were entirely among employers paying for only some of the cost of insurance, there would be a shift out of employers paying the entire premium.

We can assess the extent to which employers are shifting away from paying the full premium under two reasonable behavioral assumptions. First, it seems natural to assume that, in the absence of changes to the structure of cost-sharing, very few of those workers whose employer pays the full cost of insurance would drop coverage. Under this assumption, all of the reduction in this group represents changes in employer behavior. That is, our estimates imply that for every 10 percentage point increase in the share of family expenditures made eligible for Medicaid, there is a 0.7 percentage point reduction in the likelihood that employers will pay all of the costs of insurance. A more conservative assumption would be that coverage would have declined equally for all groups in the absence of changes in employer behavior. In this case, since 36 percent of firms pay the full cost of insurance on average, we would predict that 36 percent of the reduction in coverage would be among this group. In fact, the reduction in this group was 60 percent of the total decline. Thus, even in this case there is an estimated reduction in the share of employers paying all of the costs of insurance for their employees.

These findings may therefore explain the reduction in takeup rates associated with eligibility increases. This question cannot be answered definitively, however, without panel data on employer

${ }^{36}$ This is true because the decline in coverage in Table $5(-.115)$ is larger in magnitude than the reduction in workers whose employer paid for all of the premium $(-.068)$. 
contributions and insurance coverage among those who accept and decline employer coverage.

\section{IV.D Shifts in Who is Covered}

Since most of the people made eligible by the expansions are dependents, a natural reaction for workers may be to drop coverage of eligible dependents only, while maintaining insurance for themselves. If this happens, then along with the overall fall in coverage there should be a net shift from family to individual coverage among workers. We can examine whether there is such a response using data from the March CPS. While the survey does not indicate whether a worker is offered coverage, it does indicate who is covered by the worker's policy. We divide policies into individual coverage only, and those that also cover some other dependents. ${ }^{37}$ In each case, we count workers without employer-provided insurance as not covering any dependents. This once again avoids any bias from sampling only on workers with coverage.

We focus on married male workers over age 23 , with either a $15-44$ year-old spouse or a child (or both). The male workers are not themselves eligible, but they have dependents who are; therefore, if the decision is to drop dependent coverage and keep individual coverage, it should be concentrated in this population. Among this group, only 8 percent of those with coverage from their employer have individual coverage.

Table 6 reports regressions explaining who is covered by the worker's policy. All of the independent variables from Table 5 are included in the regression, but are not reported. The first column replicates the regression from column (4) of Table 5 for this subpopulation. There is in fact

\footnotetext{
${ }^{37}$ The survey actually asks more detailed questions about whether the policy covers one's spouse, children in the household, children outside of the household, and others. We focus on dependent coverage in general since most policies do not offer workers the ability to differentiate between dependents. Indeed, when we estimate the regressions below separately for spousal and child coverage, the results for both groups are very similar to the results for any dependent.
} 
a somewhat stronger effect of Medicaid policy on this group: a 10 percentage point rise in the fraction of family medical costs eligible for Medicaid leads to a 1.7 percentage point reduction in the probability of being covered by insurance.

As the next two columns show, there is a sizeable increase in individual coverage for workers, which is matched by a drop in dependent coverage which is larger than the overall coverage reduction in column (1). Given that we do not know the type of coverage specifically for those workers that drop coverage, we cannot infer for certain the net shift from family to individual coverage. However, since individual coverage in this population is relatively small, and since a male with individual coverage would have no incentive to drop coverage in response to Medicaid expansions, most of the overall decrease in coverage is likely coming from those with family policies. In that case, the estimates imply that, in addition to the 1.7 percent of workers who drop their employer-provided insurance, another 0.7 percent of workers are dropping their dependents and shifting to individual policies.

Thus, increases in the eligibility of family medical spending for Medicaid coverage significantly lowers the probability of worker insurance coverage. This reduction in coverage appears to arise solely from worker takeup decisions, although this may be a response to increased employer cost sharing. In addition, workers are reacting by both dropping insurance coverage entirely, and by eliminating coverage of their dependents only.

\section{V: Total Crowdout Estimates}

Having examined the sources of crowdout, we now return to estimate its total magnitude. As the previous section showed, the most appropriate specification of Medicaid effects is in terms of family eligibility. We thus reestimate equation (2) as: 
(2"') $\operatorname{COV}_{i}=\beta_{1} \%$ OWN Dollar ${ }_{i}+\beta_{2} \% O T H E R$ Dollar $r_{i}+X_{i} \beta+D_{E M O G}, \gamma_{k}+\Sigma \alpha_{s}$ state $_{i}+$

$$
\Sigma \alpha_{\mathrm{t}} \mathrm{time}_{\mathrm{i}}+\epsilon_{\mathrm{i}}
$$

$\mathrm{COV}_{\mathrm{i}}$ is again an indicator for Medicaid or private insurance coverage. \%OWN Dollar and \%OTHER Dollar split \%HIU Dollars into the share attributable to the individual child or woman, and the share attributable to all other family members. We allow insurance coverage to depend differently on these two factors. These two variables are somewhat collinear, making distinct estimation of the effects difficult; but we get almost precisely the same results if we combine the two measures into one total measure of family dollars. $\mathrm{X}$ is the set of demographic controls noted in Table 5. ${ }^{38}$ As in Table 5, we include the full set of DEMOG controls. Once again, the regressions are estimated as instrumental variables.

Table 7 presents estimates of (2"'). Results are presented for children (the first set of columns), women of child-bearing age (the second set of columns), and other adults (the third set of columns). For simplicity, we report only the coefficients on the share of HIU dollars accounted for by oneself and by others.

For children, the estimates imply that both own and other eligibility significantly affect insurance coverage. A 10 percentage point increase in family dollars attributable to own coverage raises Medicaid coverage by 3 percentage points and lowers private insurance by nearly 2 percentage points. Eligibility of other family members has an even stronger effect on Medicaid coverage than the share of dollars attributable to oneself, but a weaker effect on private coverage.

For women of child-bearing age, there is a very small effect of the woman's own potential coverage on receipt of Medicaid, which is consistent with Table 4. Medicaid coverage does respond

\footnotetext{
${ }^{38}$ If the individual is not a worker, we impute job information from the primary worker. In the case of multiple workers, we use job controls for the head of the family.
} 
to eligibility of other family members, however. Once again, own dollars have a larger effect on private coverage than do family dollars. Finally, for other adults, increased family Medicaid eligibility leads to reductions in private insurance coverage. ${ }^{39}$

For both children and women of child-bearing age, Medicaid coverage depends strongly on eligibility of other members of the family. There are two potential explanations for this finding. First, there may be substantial fixed costs of enrolling in Medicaid, such as stigma, so that only when there is significant coverage of total family dollars does the family enroll. Similarly, individuals may not sign up for Medicaid until someone in the family is sick; when more people are eligible, the likelihood that one eligible person is sick increases. Alternatively, this finding may be due to the reporting bias in the CPS discussed above. When more children are covered by Medicaid, mothers may report themselves covered by Medicaid as well. Or, parents may report all children as covered by Medicaid even if only some children are. In this case, the Medicaid increase calculated using the family dollars figure could be a overstatement of the actual Medicaid increase. ${ }^{40}$

We can convert these results into population figures to estimate the total amount of crowdout due to eligibility increases. The results of doing so are shown below. As the first row reports, the increase in the eligibility of both the child and other family members increased Medicaid coverage of children by 1.5 million persons. The decline in private coverage is about 0.7 million, however. For women of child-bearing age, there is a Medicaid increase of 0.8 million, but a reduction in

\footnotetext{
${ }^{39}$ Note that these coefficients are consistent with our finding above that most of the reduction in private coverage arises from workers dropping both themselves and their dependents, rather than dropping their dependents only. This is reflected in coefficients for other adults which are smaller, but of the same magnitude, as the coefficients for women of child-bearing age and children.

${ }^{40}$ In addition, this same type of effect may lead us to understate the reduction in private coverage: in families where dependents have been dropped due to Medicaid eligibility increases, the family may still report that all members are covered. This would lead to a further understatement of the total crowding out effect of Medicaid expansions.
} 
private coverage of the same amount; even accounting for within-family spillovers, the crowdout for this group is 100 percent. Finally, coverage of other adults falls by 0.2 million. Thus, our first estimate of the total crowdout from the Medicaid expansions is 74 percent.

Effect of Medicaid Expansions on Insurance Coverage

\begin{tabular}{lcc}
\hline & \multicolumn{2}{c}{ Change in Coverage (millions) } \\
\cline { 2 - 3 } Coverage of: & Medicaid & Private \\
\hline Children & 1.5 & -0.7 \\
Women 15-44 & 0.8 & -0.8 \\
Other Adults & --- & -0.2 \\
Total & 2.3 & -1.7 \\
& & $(-74 \%)$ \\
Implicit Coverage of Women & 0.9 & --- \\
Implicit Coverage of Children & 0.4 & --- \\
Total & 3.6 & -1.7 \\
\end{tabular}

Based on estimates in Table 7.

As noted in Section III, however, this coverage increase is an underestimate of the true increase. The Medicaid expansions explicitly did not give continuous coverage to women. Rather, they created a form of "conditional coverage" -- women are covered, but only for some expenses. As a result, women who are eligible for Medicaid in the event of pregnancy but who report themselves to be uninsured actually have some partial (conditional) insurance coverage.

Accounting for this conditional coverage is difficult, because it requires estimating both the value of pregnancy coverage only and the likelihood that uninsured women would avail themselves of this coverage if they became pregnant. Evidence from case studies of the Medicaid expansions suggests that very few women who were made eligible took advantage of this eligibility to fund 
prenatal care services. Rather, due perhaps to poor information about eligibility, most women were enrolled in Medicaid by hospitals at the time of their delivery; in fact, many hospitals have set up special departments, or contracted with outside parties, explicitly to sign up Medicaid eligibles for the program. ${ }^{41}$ We therefore proxy for the value of this conditional coverage as the dollars of expected hospital expenditures for pregnancy that an uninsured women would receive. This will overstate conditional coverage to the extent that not all of these uninsured women get signed up for Medicaid or to the extent that the Medicaid payment does not improve the care they receive.

In 1987 , the hospital share of pregnancy costs was approximately $\$ 2680$; since approximately 11 percent of 15-44 year old women are pregnant in any given year, this is about $\$ 295$ of expected coverage annually, or 25 percent of annual health spending for women of child-bearing. Between 1987 and 1992, and additional 3.7 million uninsured women were made eligible for Medicaid coverage for pregnancy-related services. Therefore, the amount of conditional coverage is the equivalent of 0.9 million people ( 3.7 million $\times 25$ percent).

In the same vein, Medicaid also provides a form of conditional coverage for some uninsured children. The fact that these children are not continuously covered by Medicaid suggests that they are not availing themselves of the insurance for the purpose of their primary medical care. Once again, however, when these children appear in the hospital, they may be signed up for Medicaid, so that they have conditional coverage for their hospital spending. On average, 44 percent of spending for children is for hospitals. Between 1987 and 1992, the number of uninsured children eligible for Medicaid coverage rose by 0.9 million, so that the conditional coverage for this group amounts to 0.4 million children ( 0.9 million $\times 44$ percent).

\footnotetext{
${ }^{41}$ See Currie and Gruber (1995) and Piper et al. (1990) for further discussion. These hospital efforts are potentially profitable because uninsured individuals pay only a small share of their bills, so that if the hospital can sign them up for Medicaid it will increase hospital reimbursement.
} 
Adding the resulting 1.3 million (statistical) persons who are conditionally covered by Medicaid to the 2.3 million direct coverage increase leads to an effective coverage increase of 3.6 million people. With this estimate, the reduction in private coverage as a percentage of the rise in effective Medicaid coverage is 47 percent. We therefore estimate the net crowdout of Medicaid at between 47 and 74 percent of the coverage increase.

While our estimates suggest substantial crowdout, they do not suggest that most of the reduction in private insurance coverage over this period is because of Medicaid crowdout. Relative the percent of the population with private health insurance in 1987, there was a 9.9 million person decline in private coverage by 1992 . Of this reduction, about 17 percent was due to crowding out. The remainder is due to macroeconomic factors, changes in the demographic mix of the population, or changes in employer behavior unrelated to Medicaid generosity.

\section{VII: Conclusions}

The past decade has witnessed substantial increases in public sector eligibility for health insurance. The percent of children who can receive Medicaid rose by 50 percent between 1987 and 1992, and the percent of women eligible for Medicaid if they are pregnant more than doubled. These expansions substantially increased Medicaid coverage -- by about 2.3 million people. The expansions did come at a price, however. As Medicaid eligibility increased, there was a direct offset in private insurance coverage, on the order of one-half to three-quarters of the Medicaid coverage increase. This reduction in private coverage largely came from workers deciding to drop their own insurance coverage, and particularly coverage of dependents, rather than through firm decisions to stop offering insurance.

It is important to note, however, that we have considered in this paper only the cost of these 
policy changes. But public sector expansions may also have important health benefits which justify these costs. Currie and Gruber (1995) find that Medicaid eligibility increases for children were associated with increases in medical care utilization and health improvements. These health improvements should be taken into account in evaluating the efficacy of eligibility changes.

More generally, our results may provide some guidance in the design of public insurance policy. The Medicaid expansions had an exclusionary structure, whereby individuals were either entirely eligible for public insurance or not eligible at all. An alternative would be to subsidize the private insurance purchase of all low income people, with a sliding scale that offers high subsidies for very low income persons but which declines as income rises. This approach would provide subsidies to everyone in a given income range, but would induce less distortion across types of

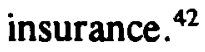

Alternatively, a waiting period could be imposed between when an individual loses private coverage and when they become eligible for Medicaid, or individuals could be excluded from Medicaid coverage entirely if they are offered but decline private coverage ${ }^{43}$ Each of these might limit the ability to move easily from private to public insurance. Exploring these types of policy designs is a clear priority for future research.

Finally, our results raise the fundamental question of how the public sector should design programs to improve the health of the poor. Expanding public insurance is one common suggestion, but this may be quite expensive, due partially to private crowdout. Another alternative to subsidized insurance is direct provision of care to the poor, in the form of better public hospitals and outpatient

\footnotetext{
${ }^{42}$ At the same time, such a sliding scale will affect labor supply incentives for those near recipiency. The net effect on work is unclear.

${ }^{43} \mathrm{Nichols}$ and Zeckhauser (1982) discuss a number of mechanisms to induce individuals to select private provision instead of public provision.
} 
care in poor areas. Direct provision of care may also cause private insurance crowdout, however, raising the costs of this policy direction as well; the extent of crowdout from public provision (as opposed to public insurance) is an unanswered question. Finally, some have suggested putting aside coverage expansions and focusing on adverse social behavior, such as smoking, drinking, firearms, and bullets (Cutler, 1995). Evaluating the costs and benefits of policies from this broad menu of public options is an important step for future research. 


\section{References}

Blank, Rebecca M., and Patricia Ruggles, "Why Do Women Use AFDC \& Food Stamps: The Dynamics of Eligibility vs. Participation", NBER Working Paper No. 4429, August 1993.

Currie, Janet, and Jonathan Gruber, "Saving Babies: The Efficacy and Cost of Medicaid Expansions", NBER Working Paper No. 4644, 1994.

Currie, Janet, and Jonathan Gruber, "Health Insurance Eligibility, Utilization of Medical Care, and Child Health", MIT mimeo, 1995.

Currie, Janet, Jonathan Gruber, and Michael Fischer, "Physician Payments and Infant Mortality: Evidence from Medicaid Fee Policy", NBER Working Paper No. 4930, November 1994.

Cutler, David M., and Brigitte C. Madrian, "Labor Market Responses to Rising Health Insurance Costs", Harvard mimeo, February 1995.

Cutler, David M., "Costs and Outcomes: The Future of Health Reform", Health Affairs, forthcoming, 1995.

Feldstein, Martin, "Social Security, Induced Retirement, and Aggregate Capital Accumulation", Journal of Political Economy, September/October 1974.

Gruber, Jonathan, "The Incidence of Mandated Maternity Benefits", American Economic Review, June 1994.

Hubbard, Glenn, Jon Skinner, and Steve Zeldes, "Precautionary Savings and Social Insurance", Journal of Political Economy, forthcoming 1995.

Nichols, Albert, and Richard Zeckhauser, "Targetting Transfers Through Restrictions on Recipients", American Economic Review, 1982, 372-377.

Piper, J.M., et al., "Effects of Medicaid Eligibility Expansion on Prenatal Care and Pregnancy Outcomes in Tennessee", Journal of the American Medical Association, 264, 1990, 2219-2223.

Schoeni, Robert, "Does AFDC Displace Familial Assistance", mimeo, 1994.

Sheiner, Louise, "Aging, Health Costs, and Wages", Federal Reserve Board mimeo, 1994.

United States General Accounting Office, Health Care Reform: Potential Difficulties in Determining Eligibility for Low-Income People, GAO-HEHF-94-176, Washington, D.C.: Government Printing Office, July 1994.

United States House of Representatives, Green Book, Washington, D.C.: Government Printing Office, 1992.

Yelowitz, Aaron S. (1993). "The Medicaid Notch, Labor Supply and Welfare Participation: Evidence from Eligibility Expansions." Mimeo, MIT. 
Figure 1(a)

Percent of Children With Different Forms of Insurance

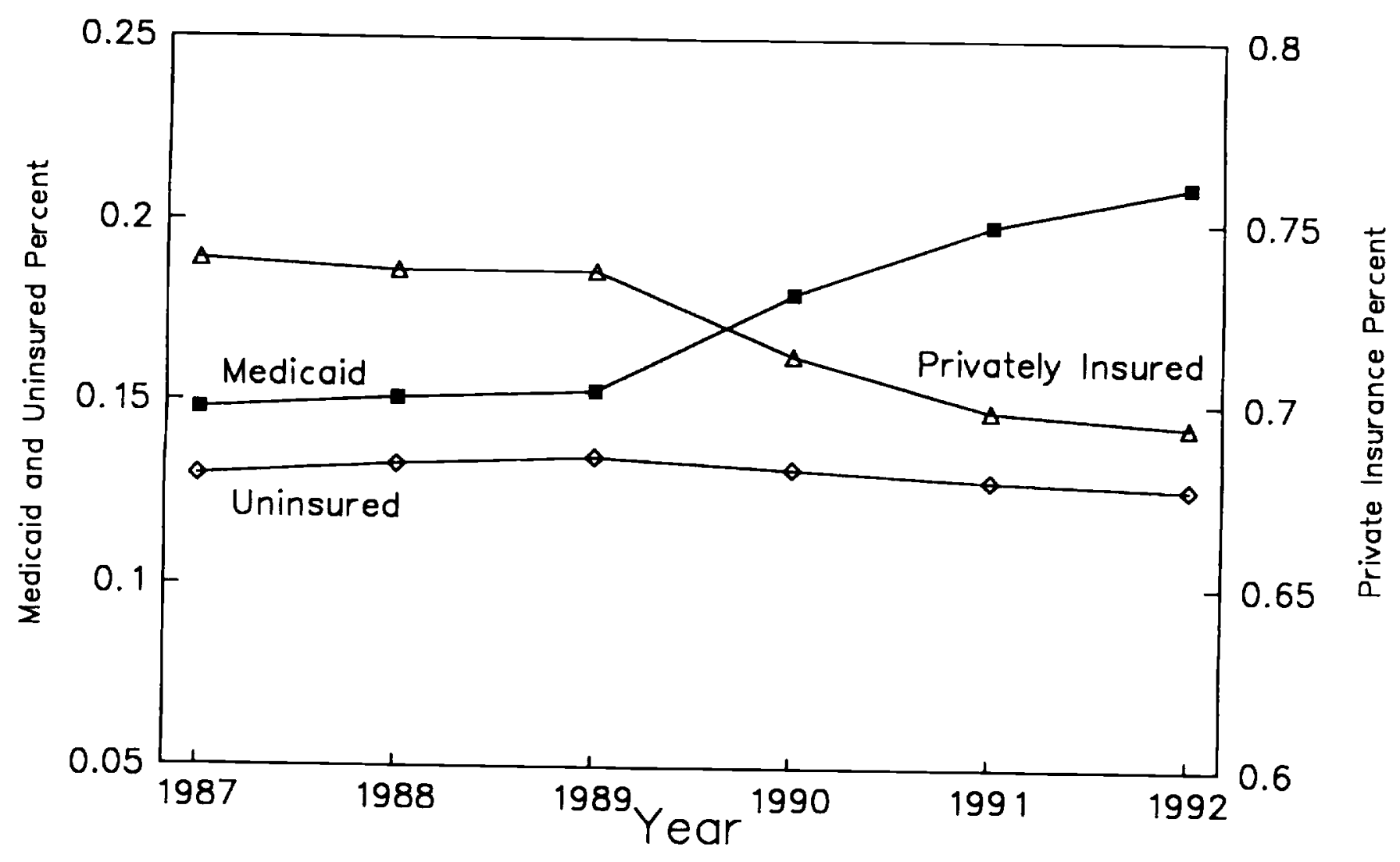


Figure 1(b)

Percent of Women 15-44 With Different Forms of Insurance

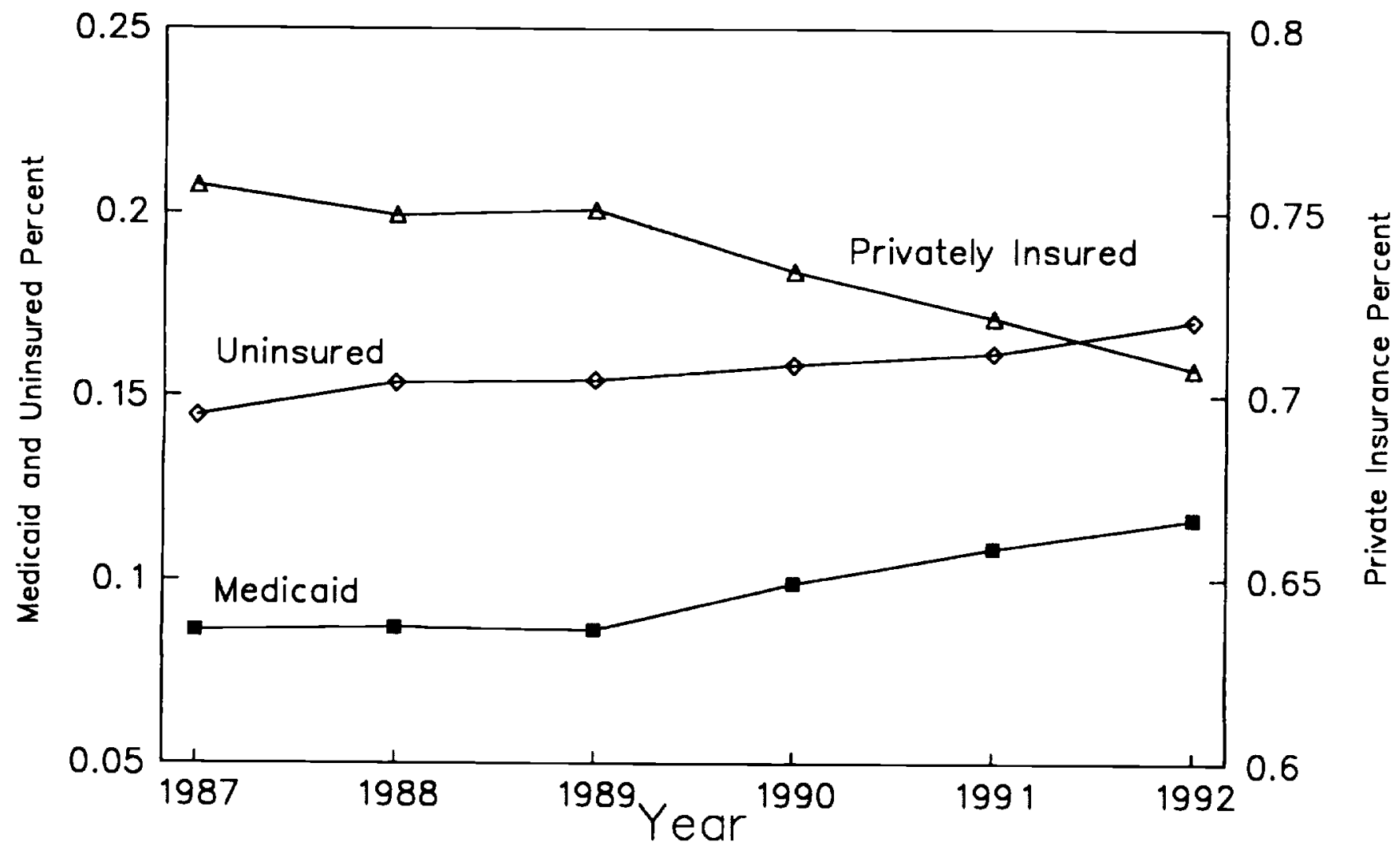


Table 1: Time Series Data on Medicaid Eligibility and Coverage

\begin{tabular}{|c|c|c|c|c|c|}
\hline \multirow[b]{2}{*}{ Year } & \multicolumn{2}{|c|}{ Percent of Children 0-18 } & \multicolumn{2}{|c|}{ Percent of Women $15-44$} & \multirow{2}{*}{$\begin{array}{c}\text { Percent of } \\
\text { HIU } \\
\text { Dollars }\end{array}$} \\
\hline & Eligible & Covered & Eligible & Covered & \\
\hline 1987 & $17.8 \%$ & $14.8 \%$ & $21.1 \%$ & $8.6 \%$ & $8.2 \%$ \\
\hline 1988 & 17.8 & 15.1 & 25.2 & 8.7 & 8.7 \\
\hline 1989 & 18.5 & 15.3 & 32.3 & 8.6 & 9.3 \\
\hline 1990 & 22.7 & 18.0 & 40.3 & 9.9 & 11.2 \\
\hline 1991 & 25.0 & 19.9 & 42.4 & 10.8 & 12.1 \\
\hline 1992 & 27.0 & 21.0 & 44.9 & 11.7 & 12.5 \\
\hline
\end{tabular}

Note: Calculations based on CPS data for 1988 through 1993. Women aged 15 through 18 are included in the child sample if dependent and in the adult sample if not dependent. Men aged 15-18 are included in the child sample if dependent. Data are weighted to national totals. 
Table 2: Sources of Insurance Coverage for the Non-Elderly Population, 1987

\begin{tabular}{lccc}
\hline & \multicolumn{3}{c}{ Insurance Status } \\
\cline { 2 - 4 } Group & Private & Public & Uninsured \\
\hline All & $76 \%$ & $14 \%$ & $14 \%$ \\
& & & \\
Children and Women of Child-Bearing Age & & & \\
Eligible in 1987 & $31 \%$ & $50 \%$ & $25 \%$ \\
Made Eligible Between 1987 and 1992 & 65 & 15 & 25 \\
Not Eligible by 1992 & 83 & 9 & 12 \\
\hline
\end{tabular}

Note: Based on authors' tabulations of the March 1988 Current Population Survey. Totals do not add to 100 percent because individuals may have more than 1 source of coverage. Data are weighted to national totals. 
Table 3: Summary Statistics for Individual Data

\begin{tabular}{lccc}
\hline & \multicolumn{3}{c}{ Sample } \\
\cline { 2 - 4 } Variable & Children & Women 15-44 & Other Adults \\
\hline Male & 0.51 & --- & 0.75 \\
White & 0.80 & 0.82 & 0.86 \\
Married & - & 0.58 & 0.63 \\
Number of Persons & 4.12 & 2.77 & 2.29 \\
Workers & & & \\
0 Workers & 0.10 & 0.08 & 0.10 \\
1 Worker & 0.35 & 0.46 & 0.47 \\
2 Workers & 0.44 & 0.40 & 0.37 \\
3+ Workers & 0.10 & 0.06 & 0.06 \\
Health Ins. Unit Type & & & \\
Male/Female & 0.73 & 0.58 & 0.63 \\
Male head & 0.04 & $-\ldots .2$ & 0.29 \\
Female head & 0.24 & 0.42 & 0.08 \\
N & 266,421 & 194,139 & 355,333 \\
\hline
\end{tabular}

Note: People aged 15 though 18 are included in the child sample if dependent and in the appropriate adult sample if not dependent. Data are weighted to national totals. 
Table 4: Regressions Explaining Coverage for Women and Children

\begin{tabular}{|c|c|c|c|c|c|c|}
\hline \multirow[b]{2}{*}{ Independent Variable } & \multicolumn{3}{|c|}{ Children } & \multicolumn{3}{|c|}{ Women } \\
\hline & Medicaid & Private & Uninsured & Medicaid & Private & Uninsured \\
\hline Eligible for Medicaid & $\begin{array}{c}0.235 \\
(0.014)\end{array}$ & $\begin{array}{r}-0.074 \\
(0.018)\end{array}$ & $\begin{array}{r}-0.119 \\
(0.016)\end{array}$ & $\begin{array}{c}0.008 \\
(0.018)\end{array}$ & $\begin{array}{r}-0.045 \\
(0.027)\end{array}$ & $\begin{array}{c}0.046 \\
(0.025)\end{array}$ \\
\hline \multicolumn{7}{|l|}{ Demographics } \\
\hline Male & $\begin{array}{c}0.002 \\
(0.001)\end{array}$ & $\begin{array}{c}-0.003 \\
(0.002)\end{array}$ & $\begin{array}{c}0.001 \\
(0.001)\end{array}$ & -- & $\ldots$ & -- \\
\hline White & $\begin{array}{r}-0.069 \\
(0.002)\end{array}$ & $\begin{array}{c}0.081 \\
(0.002)\end{array}$ & $\begin{array}{c}-0.019 \\
(0.002)\end{array}$ & $\begin{array}{l}-0.058 \\
(0.002)\end{array}$ & $\begin{array}{c}0.086 \\
(0.003)\end{array}$ & $\begin{array}{c}-0.024 \\
(0.003)\end{array}$ \\
\hline Married & -- & - & - & $\begin{array}{c}0.013 \\
(0.008)\end{array}$ & $\begin{array}{c}-0.070 \\
(0.012)\end{array}$ & $\begin{array}{r}0.018 \\
(0.011)\end{array}$ \\
\hline \multicolumn{7}{|l|}{ Health Ins, Unit } \\
\hline Number of People & $\begin{array}{c}0.025 \\
(0.001)\end{array}$ & $\begin{array}{c}-0.032 \\
(0.001)\end{array}$ & $\begin{array}{c}0.010 \\
(0.001)\end{array}$ & $\begin{array}{c}0.051 \\
(0.001)\end{array}$ & $\begin{array}{c}-0.037 \\
(0.002)\end{array}$ & $\begin{array}{l}-0.007 \\
(0.002)\end{array}$ \\
\hline Male/Female & $\begin{array}{c}-0.151 \\
(0.004)\end{array}$ & $\begin{array}{c}0.176 \\
(0.006)\end{array}$ & $\begin{array}{l}-0.056 \\
(0.005)\end{array}$ & $\begin{array}{c}-0.135 \\
(0.004)\end{array}$ & $\begin{array}{c}0.140 \\
(0.007)\end{array}$ & $\begin{array}{c}-0.023 \\
(0.006)\end{array}$ \\
\hline Male Head & $\begin{array}{l}-0.124 \\
(0.004)\end{array}$ & $\begin{array}{c}0.030 \\
(0.005)\end{array}$ & $\begin{array}{c}0.063 \\
(0.004)\end{array}$ & - & -- & - \\
\hline 0 Workers & $\begin{array}{c}0.392 \\
(0.007)\end{array}$ & $\begin{array}{c}-0.536 \\
(0.010)\end{array}$ & $\begin{array}{c}0.113 \\
(0.009)\end{array}$ & $\begin{array}{c}0.513 \\
(0.001)\end{array}$ & $\begin{array}{c}-0.650 \\
(0.015)\end{array}$ & $\begin{array}{c}0.084 \\
(0.014)\end{array}$ \\
\hline 1 Worker & $\begin{array}{c}0.044 \\
(0.003)\end{array}$ & $\begin{array}{c}-0.156 \\
(0.004)\end{array}$ & $\begin{array}{c}0.109 \\
(0.003)\end{array}$ & $\begin{array}{c}0.064 \\
(0.004)\end{array}$ & $\begin{array}{c}-0.158 \\
(0.006)\end{array}$ & $\begin{array}{c}0.076 \\
(0.006)\end{array}$ \\
\hline 2 Workers & $\begin{array}{c}0.004 \\
(0.002)\end{array}$ & $\begin{array}{c}-0.051 \\
(0.003)\end{array}$ & $\begin{array}{c}0.003 \\
(0.004)\end{array}$ & $\begin{array}{c}0.045 \\
(0.003)\end{array}$ & $\begin{array}{c}-0.040 \\
(0.004)\end{array}$ & $\begin{array}{c}0.005 \\
(0.004)\end{array}$ \\
\hline \multicolumn{7}{|l|}{ Summary Statistics } \\
\hline Dep. Var Mean & 0.174 & 0.719 & 0.131 & 0.097 & 0.736 & 0.157 \\
\hline $\mathbf{N}$ & 266,421 & 266,421 & 266,421 & 194,131 & 194,131 & 194,131 \\
\hline
\end{tabular}


Table 5: Employer and Employee Responses

\begin{tabular}{|c|c|c|c|c|c|c|c|}
\hline \multirow[b]{2}{*}{ Independent Variable } & \multicolumn{3}{|c|}{ Employee Benefits Supplements } & \multicolumn{4}{|c|}{ March Annual Demographic Supplement } \\
\hline & $\begin{array}{c}\text { Coverage } \\
\text { from } \\
\text { Employer }\end{array}$ & $\begin{array}{c}\text { Employer } \\
\text { Offers }\end{array}$ & $\begin{array}{c}\text { Takeup if } \\
\text { Offered }\end{array}$ & $\begin{array}{l}\text { Coverage } \\
\text { from } \\
\text { Employer }\end{array}$ & $\begin{array}{c}\text { Employer } \\
\text { Pays All }\end{array}$ & $\begin{array}{l}\text { Employer } \\
\text { Pays Some }\end{array}$ & $\begin{array}{l}\text { Employer } \\
\text { Pays None }\end{array}$ \\
\hline$\%$ of HIU Dollars & $\begin{array}{l}-0.183 \\
(0.092)\end{array}$ & $\begin{array}{l}-0.002 \\
(0.078)\end{array}$ & $\begin{array}{r}-0.249 \\
(0.108)\end{array}$ & $\begin{array}{r}-0.115 \\
(0.034)\end{array}$ & $\begin{array}{l}-0.068 \\
(0.033)\end{array}$ & $\begin{array}{r}-0.016 \\
(0.036)\end{array}$ & $\begin{array}{r}-0.030 \\
(0.014)\end{array}$ \\
\hline \multicolumn{8}{|l|}{ Demographics } \\
\hline Male & $\begin{array}{c}0.116 \\
(0.006)\end{array}$ & $\begin{array}{c}0.019 \\
(0.005)\end{array}$ & $\begin{array}{c}0.120 \\
(0.005)\end{array}$ & $\begin{array}{c}0.140 \\
(0.002)\end{array}$ & $\begin{array}{c}0.045 \\
(0.005)\end{array}$ & $\begin{array}{c}0.082 \\
(0.002)\end{array}$ & $\begin{array}{c}0.013 \\
(0.001)\end{array}$ \\
\hline White & $\begin{array}{c}0.008 \\
(0.006)\end{array}$ & $\begin{array}{c}0.009 \\
(0.005)\end{array}$ & $\begin{array}{c}-0.002 \\
(0.004)\end{array}$ & $\begin{array}{c}0.050 \\
(0.002)\end{array}$ & $\begin{array}{c}0.039 \\
(0.002)\end{array}$ & $\begin{array}{c}0.012 \\
(0.002)\end{array}$ & $\begin{array}{c}-0.001 \\
(0.001)\end{array}$ \\
\hline Married & $\begin{array}{c}-0.030 \\
(0.019)\end{array}$ & $\begin{array}{r}-0.005 \\
(0.016)\end{array}$ & $\begin{array}{c}-0.030 \\
(0.019)\end{array}$ & $\begin{array}{l}-0.088 \\
(0.007)\end{array}$ & $\begin{array}{c}-0.039 \\
(0.007)\end{array}$ & $\begin{array}{c}-0.044 \\
(0.008)\end{array}$ & $\begin{array}{c}-0.004 \\
(0.003)\end{array}$ \\
\hline Age 30-39 & $\begin{array}{c}0.015 \\
(0.008)\end{array}$ & $\begin{array}{c}-0.008 \\
(0.007)\end{array}$ & $\begin{array}{c}0.022 \\
(0.007)\end{array}$ & $\begin{array}{c}0.018 \\
(0.003)\end{array}$ & $\begin{array}{c}0.008 \\
(0.003)\end{array}$ & $\begin{array}{c}0.011 \\
(0.003)\end{array}$ & $\begin{array}{c}-0.001 \\
(0.001)\end{array}$ \\
\hline Age $40-49$ & $\begin{array}{c}0.022 \\
(0.010)\end{array}$ & $\begin{array}{c}-0.016 \\
(0.008)\end{array}$ & $\begin{array}{c}0.036 \\
(0.009)\end{array}$ & $\begin{array}{c}0.024 \\
(0.003)\end{array}$ & $\begin{array}{c}0.017 \\
(0.003)\end{array}$ & $\begin{array}{c}0.007 \\
(0.003)\end{array}$ & $\begin{array}{c}0.001 \\
(0.001)\end{array}$ \\
\hline Age 50-59 & $\begin{array}{c}0.029 \\
(0.011)\end{array}$ & $\begin{array}{c}-0.021 \\
(0.009)\end{array}$ & $\begin{array}{c}0.050 \\
(0.010)\end{array}$ & $\begin{array}{c}0.043 \\
(0.003)\end{array}$ & $\begin{array}{c}0.024 \\
(0.003)\end{array}$ & $\begin{array}{c}0.013 \\
(0.004)\end{array}$ & $\begin{array}{c}0.006 \\
(0.001)\end{array}$ \\
\hline Age 60-64 & $\begin{array}{c}0.006 \\
(0.014)\end{array}$ & $\begin{array}{c}-0.031 \\
(0.012)\end{array}$ & $\begin{array}{c}0.035 \\
(0.013)\end{array}$ & $\begin{array}{c}0.081 \\
(0.004)\end{array}$ & $\begin{array}{c}0.036 \\
(0.004)\end{array}$ & $\begin{array}{c}0.027 \\
(0.005)\end{array}$ & $\begin{array}{c}0.019 \\
(0.002)\end{array}$ \\
\hline Less than high school & $\begin{array}{l}-0.089 \\
(0.009)\end{array}$ & $\begin{array}{c}-0.086 \\
(0.008)\end{array}$ & $\begin{array}{c}-0.017 \\
(0.009)\end{array}$ & $\begin{array}{c}-0.108 \\
(0.003)\end{array}$ & $\begin{array}{c}-0.060 \\
(0.003)\end{array}$ & $\begin{array}{l}-0.045 \\
(0.003)\end{array}$ & $\begin{array}{c}-0.002 \\
(0.001)\end{array}$ \\
\hline High School Graduate & $\begin{array}{c}-0.031 \\
(0.006)\end{array}$ & $\begin{array}{c}-0.020 \\
(0.005)\end{array}$ & $\begin{array}{c}-0.013 \\
(0.006)\end{array}$ & $\begin{array}{c}-0.036 \\
(0.002)\end{array}$ & $\begin{array}{c}-0.027 \\
(0.002)\end{array}$ & $\begin{array}{r}-0.010 \\
(0.002)\end{array}$ & $\begin{array}{r}-0.0002 \\
(0.001)\end{array}$ \\
\hline Some College & $\begin{array}{r}-0.030 \\
(0.006)\end{array}$ & $\begin{array}{c}-0.013 \\
(0.005)\end{array}$ & $\begin{array}{r}-0.017 \\
(0.006)\end{array}$ & $\begin{array}{c}-0.027 \\
(0.002)\end{array}$ & $\begin{array}{c}-0.017 \\
(0.002)\end{array}$ & $\begin{array}{c}-0.008 \\
(0.002)\end{array}$ & $\begin{array}{c}-0.001 \\
(0.001)\end{array}$ \\
\hline \multicolumn{8}{|l|}{ Health Insurance Unit } \\
\hline Number of People & $\begin{array}{r}-0.006 \\
(0.004)\end{array}$ & $\begin{array}{c}-0.007 \\
(0.004)\end{array}$ & $\begin{array}{c}-0.002 \\
(0.004)\end{array}$ & $\begin{array}{c}-0.013 \\
(0.002)\end{array}$ & $\begin{array}{c}-0.005 \\
(0.002)\end{array}$ & $\begin{array}{c}-0.009 \\
(0.002)\end{array}$ & $\begin{array}{c}-0.000 \\
(0.001)\end{array}$ \\
\hline Male/Female Head & $\begin{array}{c}-0.062 \\
(0.020)\end{array}$ & $\begin{array}{c}0.012 \\
(0.017)\end{array}$ & $\begin{array}{l}-0.082 \\
(0.020)\end{array}$ & $\begin{array}{c}-0.002 \\
(0.008)\end{array}$ & $\begin{array}{c}-0.019 \\
(0.008)\end{array}$ & $\begin{array}{r}0.022 \\
(0.009)\end{array}$ & $\begin{array}{l}-0.007 \\
(0.004)\end{array}$ \\
\hline
\end{tabular}


Table 5 (continued)

\begin{tabular}{|c|c|c|c|c|c|c|c|}
\hline \multirow[b]{2}{*}{ Independent Variable } & \multicolumn{3}{|c|}{ Employee Benefits Supplements } & \multicolumn{4}{|c|}{ March Annual Demographic Supplement } \\
\hline & $\begin{array}{l}\text { Coverage } \\
\text { from } \\
\text { Employer }\end{array}$ & $\begin{array}{c}\text { Employer } \\
\text { Offers }\end{array}$ & $\begin{array}{c}\text { Takeup if } \\
\text { Offered }\end{array}$ & $\begin{array}{c}\text { Coverage } \\
\text { from } \\
\text { Employer }\end{array}$ & $\begin{array}{c}\text { Employer } \\
\text { Pays All } \\
\end{array}$ & $\begin{array}{l}\text { Employer } \\
\text { Pays Some } \\
\end{array}$ & $\begin{array}{l}\text { Employer } \\
\text { Pays None }\end{array}$ \\
\hline Male Head & $\begin{array}{c}-0.123 \\
(0.012)\end{array}$ & $\begin{array}{c}-0.017 \\
(0.011)\end{array}$ & $\begin{array}{l}-0.124 \\
(0.012)\end{array}$ & $\begin{array}{c}-0.170 \\
(0.005)\end{array}$ & $\begin{array}{c}-0.059 \\
(0.005)\end{array}$ & $\begin{array}{l}-0.090 \\
(0.005)\end{array}$ & $\begin{array}{c}-0.021 \\
(0.002)\end{array}$ \\
\hline 1 Worker & $\begin{array}{c}0.069 \\
(0.011)\end{array}$ & $\begin{array}{c}0.027 \\
(0.010)\end{array}$ & $\begin{array}{c}0.053 \\
(0.010)\end{array}$ & $\begin{array}{c}0.062 \\
(0.004)\end{array}$ & $\begin{array}{c}0.001 \\
(0.004)\end{array}$ & $\begin{array}{c}0.051 \\
(0.004)\end{array}$ & $\begin{array}{c}0.010 \\
(0.002)\end{array}$ \\
\hline 2 Workers & $\begin{array}{c}0.020 \\
(0.010)\end{array}$ & $\begin{array}{c}0.015 \\
(0.009)\end{array}$ & $\begin{array}{c}0.010 \\
(0.010)\end{array}$ & $\begin{array}{c}0.019 \\
(0.003)\end{array}$ & $\begin{array}{c}0.005 \\
(0.003)\end{array}$ & $\begin{array}{c}0.011 \\
(0.004)\end{array}$ & $\begin{array}{c}0.003 \\
(0.001)\end{array}$ \\
\hline \multicolumn{8}{|l|}{ Job Characteristics } \\
\hline Full-Time & $\begin{array}{c}0.356 \\
(0.007)\end{array}$ & $\begin{array}{c}0.181 \\
(0.006)\end{array}$ & $\begin{array}{c}0.367 \\
(0.007)\end{array}$ & -- & -- & -- & -- \\
\hline Full-Time, Full-Year & --- & - & $\cdots$ & $\begin{array}{c}0.393 \\
(0.003)\end{array}$ & $\begin{array}{c}0.161 \\
(0.003)\end{array}$ & $\begin{array}{c}0.230 \\
(0.003)\end{array}$ & $\begin{array}{c}0.003 \\
(0.001)\end{array}$ \\
\hline Part-Time, Full-Year & - & -- & -- & $\begin{array}{c}0.104 \\
(0.003)\end{array}$ & $\begin{array}{c}0.037 \\
(0.003)\end{array}$ & $\begin{array}{c}0.066 \\
(0.004)\end{array}$ & $\begin{array}{c}0.001 \\
(0.001)\end{array}$ \\
\hline Full-Time, Part-Year & $\cdots$ & -- & $\cdots$ & $\begin{array}{c}0.185 \\
(0.003)\end{array}$ & $\begin{array}{c}0.083 \\
(0.003)\end{array}$ & $\begin{array}{c}0.095 \\
(0.003)\end{array}$ & $\begin{array}{c}0.007 \\
(0.001)\end{array}$ \\
\hline State/Year Unemployment Rate & $\begin{array}{c}0.001 \\
(0.002)\end{array}$ & $\begin{array}{c}0.002 \\
(0.002)\end{array}$ & $\begin{array}{c}0.001 \\
(0.002)\end{array}$ & $\begin{array}{c}0.0002 \\
(0.0008)\end{array}$ & $\begin{array}{c}-0.005 \\
(0.001)\end{array}$ & $\begin{array}{r}0.006 \\
(0.001)\end{array}$ & $\begin{array}{r}-0.0004 \\
(0.0003)\end{array}$ \\
\hline \multicolumn{8}{|l|}{ Summary Statistics } \\
\hline Dependent Variable Mean & 0.676 & 0.808 & 0.837 & 0.598 & 0.217 & 0.350 & 0.030 \\
\hline $\mathbf{N}$ & 38,460 & 38,528 & 31,201 & 391,851 & 391,851 & 391,851 & 391,851 \\
\hline
\end{tabular}


Table 6: The Effect of Medicaid Eligibility on Own and Dependent Coverage For Men with Dependents Potentially Eligible for Medicaid

\begin{tabular}{|c|c|c|c|}
\hline \multirow[b]{2}{*}{ Indepedent Variable } & \multirow{2}{*}{$\begin{array}{c}\text { Any } \\
\text { Employer } \\
\text { Coverage }\end{array}$} & \multicolumn{2}{|c|}{ Who Covered in Family } \\
\hline & & Individual & Dependents \\
\hline$\%$ of HIU Dollars & $\begin{array}{r}-0.172 \\
(0.057)\end{array}$ & $\begin{array}{c}0.066 \\
(0.038)\end{array}$ & $\begin{array}{c}-0.237 \\
(0.061)\end{array}$ \\
\hline \multicolumn{4}{|l|}{ Summary Statistics } \\
\hline Dependent Variable Mean & 0.689 & 0.081 & 0.608 \\
\hline $\mathbf{N}$ & 119,000 & 119,000 & 119,000 \\
\hline
\end{tabular}

Note: The sample is male workers aged 24-64, who have a woman of child-bearing age or child in their HIU. All regressions have the same set of controls as in Table 5. Data are weighted to national totals. 
Table 7: Regressions Explaining Net Change in Medicaid and Private Insurance Coverage

\begin{tabular}{|c|c|c|c|c|c|c|}
\hline \multirow[b]{2}{*}{ Independent Variable } & \multicolumn{2}{|c|}{ Children } & \multicolumn{2}{|c|}{ Women $15-44$} & \multicolumn{2}{|c|}{ Other Adults } \\
\hline & Medicaid & $\begin{array}{c}\text { Private } \\
\text { Insurance }\end{array}$ & Medicaid & $\begin{array}{c}\text { Private } \\
\text { Insurance }\end{array}$ & Medicaid & $\begin{array}{c}\text { Private } \\
\text { Insurance }\end{array}$ \\
\hline \%Own Dollars & $\begin{array}{c}0.282 \\
(0.019)\end{array}$ & $\begin{array}{l}-0.200 \\
(0.024)\end{array}$ & $\begin{array}{c}0.064 \\
(0.028)\end{array}$ & $\begin{array}{c}-0.310 \\
(0.044)\end{array}$ & - & - \\
\hline \%Other Dollars & $\begin{array}{c}0.481 \\
(0.021)\end{array}$ & $\begin{array}{r}-0.162 \\
(0.026)\end{array}$ & $\begin{array}{c}0.523 \\
(0.026)\end{array}$ & $\begin{array}{r}-0.134 \\
(0.041)\end{array}$ & - & $\begin{array}{r}-0.171 \\
(0.034)\end{array}$ \\
\hline \multicolumn{7}{|l|}{ Summary Statistics } \\
\hline Dependent Variable Mean & 0.174 & 0.719 & 0.097 & 0.736 & $\cdots$ & 0.761 \\
\hline $\mathbf{N}$ & 266,421 & 266,421 & 194,139 & 194,139 & $\ldots$ & 355,333 \\
\hline
\end{tabular}

Note: The Table includes the same set of controls as in Table 5. Information about work conditions is imputed for non-workers, based on the primary worker in the family. Data are weighted to national totals. 


\section{Appendix Table 1: The Medicaid Expansions}

Deficit Reduction Act, 1984: Effective October 1, 1984. Required states to extend Medicaid coverage to children born after September 30,1983, if those children lived in families that were income-eligible for AFDC.

Omnibus Budget Reconciliation Act, 1986: Effective April 1, 1987. Permitted states to extend Medicaid coverage to children in families with incomes below the federal poverty level. Beginning in fiscal year 1988, states could increase the age cutoff by one year each year, until all children under age five were covered.

Omnibus Budget Reconciliation Act, 1987: Effective July 1, 1988. Permitted states to cover children under age 2, 3, 4, or 5, who were born after September 30, 1983. Effective October 1, 1988, states could expand coverage to children under age 8 born after September 30, 1983. Allows states to extend Medicaid eligibility to infants up to one year of age in families with incomes up to $185 \%$ of the federal poverty level. States were required to cover children through age 5 in fiscal year 1989, and through age 6 in fiscal year 1990, if the families met AFDC income standards.

Medicare Catastrophic Coverage Act, 1988: Effective July 1, 1989. States were required to cover infants up to age on in families with incomes less than $75 \%$ of the federal poverty level. Effective July 1,1990 , the income threshold was raised to $100 \%$ of poverty.

Family Support Act, 1988: Effective April 1, 1990. States were required to continue Medicaid coverage for 12 months among families who had received AFDC in three of the previous six months, but who had become ineligible because of earnings.

Omnibus Budget Reconciliation Act, 1989: Effective April 1, 1990. Required states to extend Medicaid eligibility to children up to age 6 with family incomes up to $133 \%$ of the federal poverty line.

Omnibus Budget Reconciliation Act, 1990: Effective July 1, 1991. States were required to cover all children under age 19 who were born after September 30, 1983 and whose family incomes were below $100 \%$ of the Federal poverty level. 
Appendix Table 2:

Expected Health Care Costs by Age and Sex

\begin{tabular}{lcc}
\hline & \multicolumn{2}{c}{ Sex } \\
\cline { 2 - 3 } Age & Male & Female \\
\hline 0 & $\$ 2,486$ & $\$ 2,486$ \\
1 & 1,266 & 1,266 \\
$2-5$ & 450 & 450 \\
$6-9$ & 399 & 399 \\
$10-14$ & 537 & 537 \\
$15-18$ & 930 & 930 \\
$19-29$ & 625 & 1,228 \\
$30-39$ & 724 & 1,350 \\
$40-49$ & 1,326 & 1,518 \\
$50-59$ & 1,979 & 2,115 \\
$60-64$ & 2,865 & 2,277 \\
$65-74$ & 4,142 & 3,662 \\
$75-84$ & 4,504 & 4,812 \\
$85+$ & 5,470 & 5,736 \\
\hline
\end{tabular}

Source: National Medical Expenditure

Survey. Data are weighted to national totals. Pregnancy cost is $\$ 3,996$. 